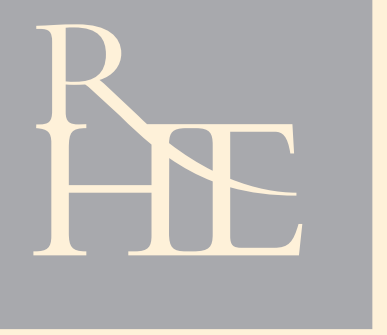

$2^{\mathrm{a}} \mathrm{EPOCA}$

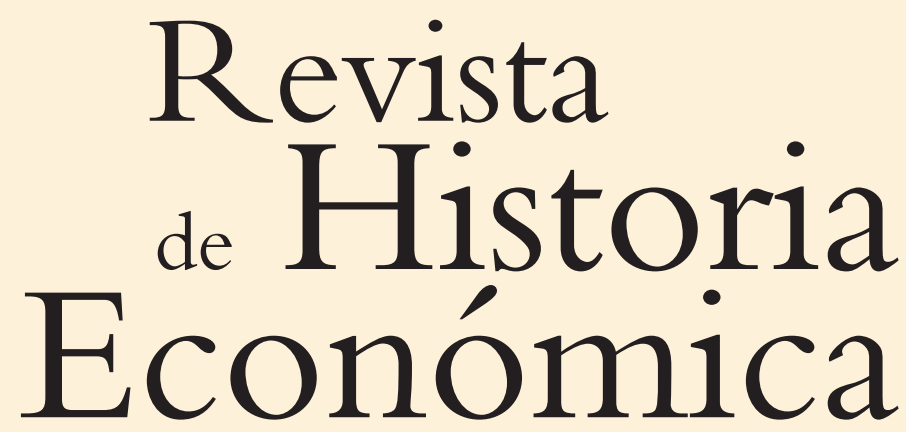

№2 - Otoño 2006 - Año XXIV Journal of Iberian and Latin American Economic History

Albert Carreras, Concepción García-Iglesias y Juha Kilponen: Un siglo y medio de velocidad de circulación del dinero en España: estimación y determinantes - Andrés Gallo: Political Institutions and Economic Policy: Rural renter legislation in Argentina, 1912-1942 - Roy Hora: El perfil económico de la elite de Buenos Aires en las décadas centrales del siglo XIX - Jordi Maluquer de Motes i Bernet: "La paradisíaca estabilidad de la anteguerra». Elaboración de un índice de precios de consumo en España, 1830-1936 • M. ${ }^{a}$ Teresa Sanchís Llopis: The spanish economic «miracle»: A disaggregated approach to productivity growth, 1958-1975 


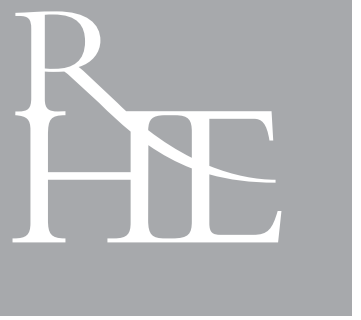

$2^{\text {a }} \mathrm{EPOCA}$

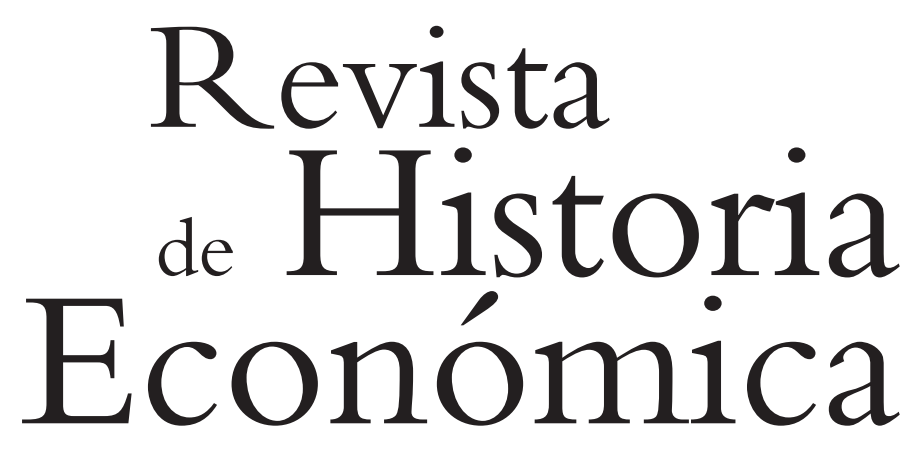

№2 - Otoño 2006 - Año XXIV Journal of Iberian and Latin American Economic History 
La correspondencia con la RHE-JILAEH debe dirigirse a rhe-jilaeh@uc3m.es

o

al Director responsable

Antonio Tena

(antonio.tena@uc3m.es)

Departamento Historia Económica

Universidad Carlos III de Madrid

c/ Madrid, $126 \bullet 28903$ Getafe

Madrid (España)

Tel. (34) 916249621

Suscripciones:

MARCIAL PONS

C/ San Sotero, 6 - 28037 Madrid (España)

Teléfono (34) 9130433 03. Fax (34) 913272367

revistas@marcialpons.es

\title{
PRECIO 2006*
}

\begin{tabular}{lc|c} 
& ESPAÑA & EXTRANJERO \\
Suscripción & $65 €$ & $90 €$ \\
\cline { 2 - 3 } Número suelto & $25 €$ & $35 €$ \\
\cline { 2 - 3 } Número extra & $45 €$ & $60 €$ \\
\cline { 2 - 3 }
\end{tabular}

* Iva no incluido

\author{
Distribuye: \\ MARCIAL PONS
}

Depósito legal: M. 29.208-1983

ISSN: 0212-6109

Impresión: EleCÉ, INDUSTRIA GRÁFICA, S. L. 


\section{SUMARIO}

\section{ARTÍ́cULOS}

Un siglo y medio de velocidad de circulación del dinero en España: estimación y determinantes

ALBERT CARRERAS, CONCEPCIÓN GARCÍA-IGLESIAS y JUHA KILPONEN

Political Institutions and Economic Policy: rural renter legislation in Argentina, 1912-1942 ANDRÉS GALLO

El perfil económico de la elite de Buenos Aires en las décadas centrales del siglo XIX

ROY HORA

«La paradisíaca estabilidad de la anteguerra». Elaboración de un índice de precios de consumo en España, 1830-1936 JORDI MALUQUER DE MOTES I BERNET

The spanish economic «miracle»: a disaggregated approach to productivity growth, 1958-1975 


\section{ARTículos}

